\title{
EDITORIAL
}

\section{Special issue on the Asian Congress on Biotechnology 2011}

\author{
Bang-Ce YE* (凶) \\ School of Biotechnology, East China University of Science and Technology, Shanghai 200237, China
}

(C) Higher Education Press and Springer-Verlag Berlin Heidelberg 2012

The Asian Congress on Biotechnology 2011 (ACB-2011), was held on May 12, 2011 in Shanghai. The theme for ACB-2011 is "Biotechnology for Better Life". ACB-2011 aims to provide a forum for biotechnologists and biochemical engineers from Asia and other regions of the world, in which people could exchange ideas and findings in biotechnology research and development, share the experiences in advancing biotechnological development or business adventure, and then enhance further research and business cooperation.

In light of this tenet, this special issue contains 17 research papers selected from several countries of Asia Pacific including China, Russia, America, Japan, Indonesia, India, Malaysia and Thailand.

Our world is facing various challenges including environmental deterioration, energy crisis, shortage of natural resources, and imbalances in social and economic development. Life sciences and biochemical engineering are expected to play an important role in addressing those problems to meet the remaining and emerging needs of our society.

This special issue covers a wide range of the hottest research topics in biochemical science and bioengineering, involving in selective breeding strains for amino acid production, biological pretreatment, clean renewable energy mining, heavy metal biosorption and treatment and novel biosensor exploitation based on immunology etc. These cntting-edge research works, which although do not cover the full scope of studies in biochemical science and bioengineering due to page limitations, can still provide readers with brief track references to facilitate the development of new technologies in these fields.

During the organizing of this special issue, we got invaluable help from many scientists. They provided careful peer-reviews on the selected papers with many useful comments and suggestions, which help to enhance the quality of the papers for authors. Without the help of these peer-reviewers, this special issue is not possible to be published.

Finally, as the Guest Editor, I would like to take this opportunity to express my high appreciate to all of the people all the authors and co-authors and reviewers, for their contributions and consistent support to this special issue.

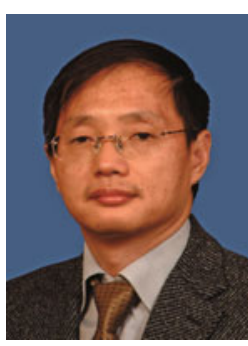

Bang-Ce YE, Ph.D, Professor, Deputy Director of State Key Laboratory of Bioreactor Engineering, East China University of Science and Technology. His research interests concentrate in analytical biotechnology and systems biotechnology. He has published over 50 papers in peer-reviewed international journals, such as Angewandte Chemie International Edition, Journal of the American Chemical Society, the Proceedings of the National Academy of Sciences of the United States of America, Chemical Communications, Analytical Chemistry, Applied and Environmental Microbiology.

E-mail: bcye@ecust.edu.cn

*Bang-Ce YE is the guest editor of the special issue on the Asian Congress on Biotechnology 2011 